\title{
Numerical Investigation of Laminar Film Condensation at Low Pressure on a Condenser Tube of an Adsorption Chiller
}

\author{
Yusuf Yılmaz ${ }^{1}$, Gamze Gediz Ilis ${ }^{2}$, Hasan Demir ${ }^{3}$ \\ ${ }^{1}$ Istanbul Okan University, Mechatronic Engineering Program \\ Akfirat, Tuzla, Istanbul, Turkey \\ yusufyilmaz@karbonsan.com.tr \\ ${ }^{2}$ Istanbul Okan University, Mechanical Engineering Department \\ Akfirat, Tuzla, Istanbul, Turkey \\ gamze.gediz@okan.edu.tr \\ ${ }^{3}$ Osmaniye Korkut Ata University, Chemical Engineering Department \\ Osmaniye, Turkey \\ demirhasan.hd@gmail.com
}

\begin{abstract}
In this paper, the film condensation over the condenser horizontal pipe is taken into consideration. The condensation is occurred at low pressure and the flow stream is not only from one direction but also from all around the condenser tube. The NavierStokes equations will be solved for liquid and vapor phases by assuming laminar, incompressible, Newtonian, and viscous fluid flow. The condensation rate is analysed and the effect of the condensation on the performance of the adsorption chiller is handled in this study.
\end{abstract}

Keywords: Film condensation, Adsorption, CFD.

\section{Introduction}

Nowadays, new air conditioning systems are researched for the preventing global warming. Air conditioning systems are classified as thermally and mechanically driven air conditioning systems. Adsorption heat pump (AHP), a kind of thermally driven heat pump, is an effective system that is able to utilize thermal energy, solar energy and the heat from an industrial application. Adsorption heat pumps have many advantages such as lower operating cost, having no vibration and noise and being environmentally friendly. On the other hand, the most important drawback of the adsorption chillers is their low COP values.

In order to increase the COP values, the component design gets importance. For this reason, the heat and mass transfer inside of the adsorbent bed should be accelerated for the cooling performance [1,2]. A considerable number of researchers focus on the performance improvement of the adsorption chillers [3, 4]. COP improvement is not limited with the adsorbent bed design but also directly affected by the evaporator and condenser design of the adsorption chiller. Condensation over the tubes of the condenser should be analyzed well for the performance improvement of the adsorption chiller.

Condensation on horizontal tubes is very important for the heat exchangers in refrigeration and air conditioning processes. Heterogeneous condensation can lead to dropwise or film condensation modes. Dropwise condensation occurs when the liquid fails to wet the surface and form a film. Droplets that stick to the surface are seen over the surface. If it is a film condensation, droplets wet the surface and form a liquid film. The liquid film flows as a result of gravity. Filmwise is one of the most used forms for the engineering problems and starts with Nusselt [5]. There are basically two types of theoretical investigations can be found for the condensation. These are liquid phase and liquid+vapour models [6-9].

Laminar film condensation on an inclined circular tube is analyzed for free and forced convection by Mosaad [10]. The comparison is performed with the previous studies and good comparison is found. Steam air mixture laminar film condensation on horizontal circular tube is investigated numerically.

Another steam air mixture condensation problem on a horizontal tube is handled by Chen and Lin [11]. The effect of Re number on condensate film thickness, the effect of dimensionless group for the ratio of gravity to mixture velocity, wall temperature, and mass fraction in free stream on heat transfer are analysed in detail. 
In the numerical study of Asbik et al. [12], condensation on elliptic cylinder and on a bank of elliptical tubes where the pure saturated vapour flowing in the direction of gravity is analyzed. Temperature, velocity distribution, and heat transfer coefficient of the fully developed flow are carried out with a fully implicit finite difference scheme. The inertia and convection term are taken into consideration. They found goog agreement on the heat transfer in interellipse space.

Saleh and Ormiston [13] are worked on two-phase numerical model of film condensation of pure vapour. The model predicts the full viscous flow and heat and mass transfer for the vapour around the tube. They used a dynamically moving computational grid Eulerian method that tracks the phase interface sharply. The model was used to perform a numerical analysis of laminar film condensation from downward flowing vapour over an isothermal horizontal tube. In their another study [14],they taken the same problem and solved it with a model uses the elliptic Navier- Stokes equations and predicts the full viscous flow and heat and mass transfer in the mixture and in the entire condensate film from the top of the tube to the falling film below the tube.

In this study, the film condensation over the condenser horizontal pipe will be taken into consideration. The unity of the study is the condensation is occurred at low pressure and the flow stream is not only from one direction but also from all around the condenser tube. The Navier-Stokes equations will be solved for liquid and vapor phases by assuming laminar, incompressible, Newtonian, and viscous fluid flow. The free stream flow of water vapor on the condenser pipe will be taken as $10 \mathrm{kPa}$ which is the condenser pressure of the adsorption chiller. The wall temperature of the condenser pipe will be assumed as constant at $20^{\circ} \mathrm{C}$. The condensation rate will be analysed and the effect of the condensation on the performance of the adsorption chiller will be handled in this study.

\section{Mathematical Model}

\subsection{Problem Statement}

The problem which is handled is shown in Fig. 1. As illustrated, the condensation pipe is located inside of the adsorbent bed which is separated by a stainless steel mesh. During desorption, the water vapour which is at $10 \mathrm{kPa}$ starts to flow over the condenser pipe which is at constant the surface temperature at $20^{\circ} \mathrm{C}$ with $\mathrm{Re}=50$. The water vapour condenses on the condenser pipe surface, forming a thin film of condensate with thickness $\delta$. The gas phase separated by liquid-mixture interface from condensate film surface. The condensate film descends as free falling film below the bottom of the tube.

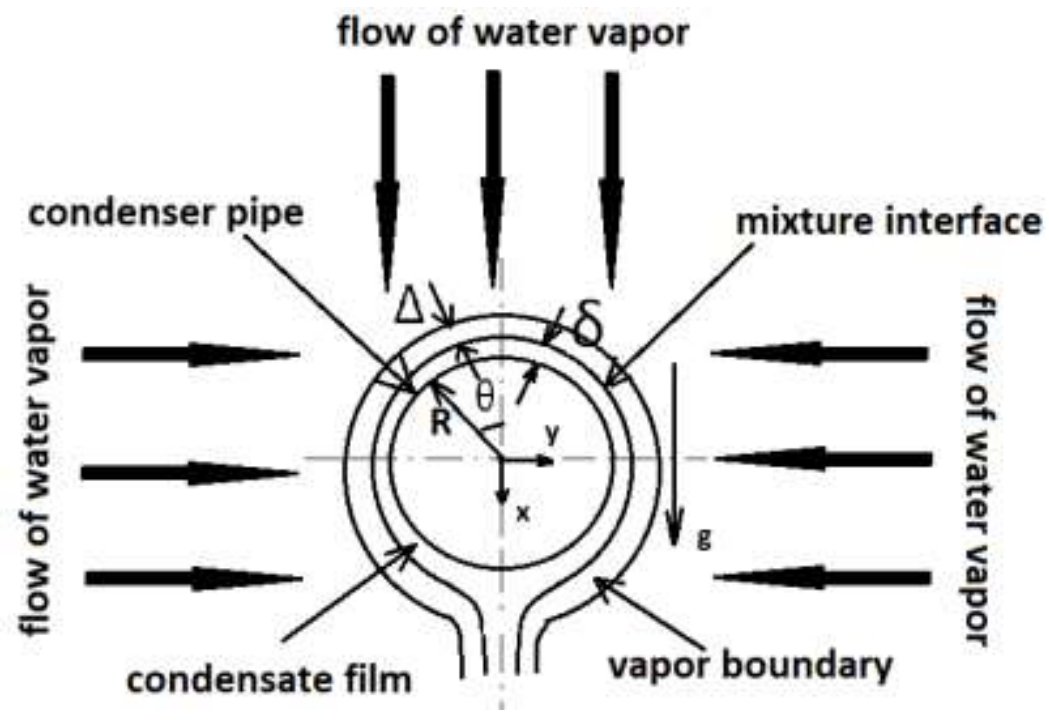

Fig. 1: Considered Problem. 


\subsection{Governing Equations and Boundary Conditions}

Conservation of mass, momentum and energy equations for vapour and liquid phases are applied to obtain the governing equations. The assumptions are listed below;

- The flow is considered as laminar, incompressible, viscous, and Newtonian.

- $\delta$ and $\Delta$ are very small when compared with $\mathrm{R}$.

- Thermophysical properties are assumed constant.

- Vapour is at saturated temperature.

- Smooth interface is assumed.

Liquid Region Equations:

$$
\begin{gathered}
\frac{\partial}{\partial x}\left(\rho_{\mathrm{l}} \mathrm{U}_{\mathrm{l}}\right)+\frac{\partial}{\partial y}\left(\rho_{\mathrm{l}} \mathrm{V}_{\mathrm{l}}\right)=0 \\
\frac{\partial}{\partial t}\left(\rho_{\mathrm{l}} \mathrm{U}_{\mathrm{l}}\right)+\frac{\partial}{\partial x}\left(\rho_{\mathrm{l}} \mathrm{U}_{\mathrm{l}} \mathrm{U}_{\mathrm{l}}\right)+\frac{\partial}{\partial y}\left(\rho_{\mathrm{l}} \mathrm{V}_{\mathrm{l}} \mathrm{U}_{\mathrm{l}}\right)=-\frac{\partial \mathrm{P}_{\mathrm{l}}}{\partial x}+\frac{\partial}{\partial x}\left(\mu_{\mathrm{l}} \frac{\partial \mathrm{U}_{\mathrm{l}}}{\partial x}\right)+\frac{\partial}{\partial y}\left(\mu_{\mathrm{l}} \frac{\partial \mathrm{U}_{\mathrm{l}}}{\partial y}\right)+\rho_{\mathrm{l}} \mathrm{g} \\
\frac{\partial}{\partial t}\left(\rho_{\mathrm{l}} \mathrm{V}_{\mathrm{l}}\right)+\frac{\partial}{\partial x}\left(\rho_{\mathrm{l}} \mathrm{U}_{\mathrm{l}} \mathrm{V}_{\mathrm{l}}\right)+\frac{\partial}{\partial y}\left(\rho_{\mathrm{l}} \mathrm{V}_{\mathrm{l}} \mathrm{V}_{\mathrm{l}}\right)=-\frac{\partial \mathrm{P}_{\mathrm{l}}}{\partial y}+\frac{\partial}{\partial x}\left(\mu_{\mathrm{l}} \frac{\partial \mathrm{V}_{\mathrm{l}}}{\partial x}\right)+\frac{\partial}{\partial y}\left(\mu_{\mathrm{l}} \frac{\partial \mathrm{V}_{\mathrm{l}}}{\partial y}\right) \\
\frac{\partial}{\partial t}\left(\rho_{\mathrm{l}} \mathrm{C}_{\mathrm{pl}} \mathrm{T}_{\mathrm{l}}\right)+\frac{\partial}{\partial x}\left(\rho_{\mathrm{l}} \mathrm{U}_{\mathrm{l}} \mathrm{C}_{\mathrm{pl}} \mathrm{T}_{\mathrm{l}}\right)+\frac{\partial}{\partial y}\left(\rho_{\mathrm{l}} \mathrm{V}_{\mathrm{l}} \mathrm{C}_{\mathrm{pl}} \mathrm{T}_{\mathrm{l}}\right)=\frac{\partial}{\partial x}\left(\mathrm{k}_{\mathrm{l}} \frac{\partial \mathrm{T}_{\mathrm{l}}}{\partial x}\right)+\frac{\partial}{\partial y}\left(\mathrm{k}_{\mathrm{l}} \frac{\partial \mathrm{T}_{\mathrm{l}}}{\partial y}\right)
\end{gathered}
$$

Vapour Region Equations:

$$
\begin{gathered}
\frac{\partial}{\partial x}\left(\rho_{\mathrm{v}} \mathrm{U}_{\mathrm{v}}\right)+\frac{\partial}{\partial y}\left(\rho_{\mathrm{v}} \mathrm{V}_{\mathrm{v}}\right)=0 \\
\frac{\partial}{\partial t}\left(\rho_{\mathrm{v}} \mathrm{U}_{\mathrm{v}}\right)+\frac{\partial}{\partial x}\left(\rho_{\mathrm{v}} \mathrm{U}_{\mathrm{v}} \mathrm{U}_{\mathrm{v}}\right)+\frac{\partial}{\partial y}\left(\rho_{\mathrm{v}} \mathrm{V}_{\mathrm{v}} \mathrm{U}_{\mathrm{v}}\right)=-\frac{\partial \mathrm{P}_{\mathrm{v}}}{\partial x}+\frac{\partial}{\partial x}\left(\mu_{\mathrm{v}} \frac{\partial \mathrm{U}_{\mathrm{v}}}{\partial x}\right)+\frac{\partial}{\partial y}\left(\mu_{\mathrm{v}} \frac{\partial \mathrm{U}_{\mathrm{v}}}{\partial y}\right)+\rho_{\mathrm{v}} \mathrm{g} \\
\frac{\partial}{\partial t}\left(\rho_{\mathrm{v}} \mathrm{V}_{\mathrm{v}}\right)+\frac{\partial}{\partial x}\left(\rho_{\mathrm{v}} \mathrm{U}_{\mathrm{v}} \mathrm{V}_{\mathrm{v}}\right)+\frac{\partial}{\partial y}\left(\rho_{\mathrm{v}} \mathrm{V}_{\mathrm{v}} \mathrm{V}_{\mathrm{v}}\right)=-\frac{\partial \mathrm{P}_{\mathrm{v}}}{\partial y}+\frac{\partial}{\partial x}\left(\mu_{\mathrm{v}} \frac{\partial \mathrm{V}_{\mathrm{v}}}{\partial x}\right)+\frac{\partial}{\partial y}\left(\mu_{\mathrm{v}} \frac{\partial \mathrm{V}_{\mathrm{v}}}{\partial y}\right) \\
\frac{\partial}{\partial t}\left(\rho_{\mathrm{v}} \mathrm{C}_{\mathrm{pv}} \mathrm{T}_{\mathrm{v}}\right)+\frac{\partial}{\partial x}\left(\rho_{\mathrm{v}} \mathrm{U}_{\mathrm{v}} \mathrm{C}_{\mathrm{pv}} \mathrm{T}_{\mathrm{v}}\right)+\frac{\partial}{\partial y}\left(\rho_{\mathrm{v}} \mathrm{V}_{\mathrm{v}} \mathrm{C}_{\mathrm{pv}} \mathrm{T}_{\mathrm{v}}\right)=\frac{\partial}{\partial x}\left(\mathrm{k}_{\mathrm{v}} \frac{\partial \mathrm{T}_{\mathrm{v}}}{\partial x}\right)+\frac{\partial}{\partial y}\left(\mathrm{k}_{\mathrm{v}} \frac{\partial \mathrm{T}_{\mathrm{v}}}{\partial y}\right)
\end{gathered}
$$

The model which is modelled for CFD analysis is given in Figure 2. The half of the model is taken into consideration in order to reduce the number of mesh and run time and left hand side is the symmetry line. Based on that mesh, the boundary conditions are given in Table 1. 


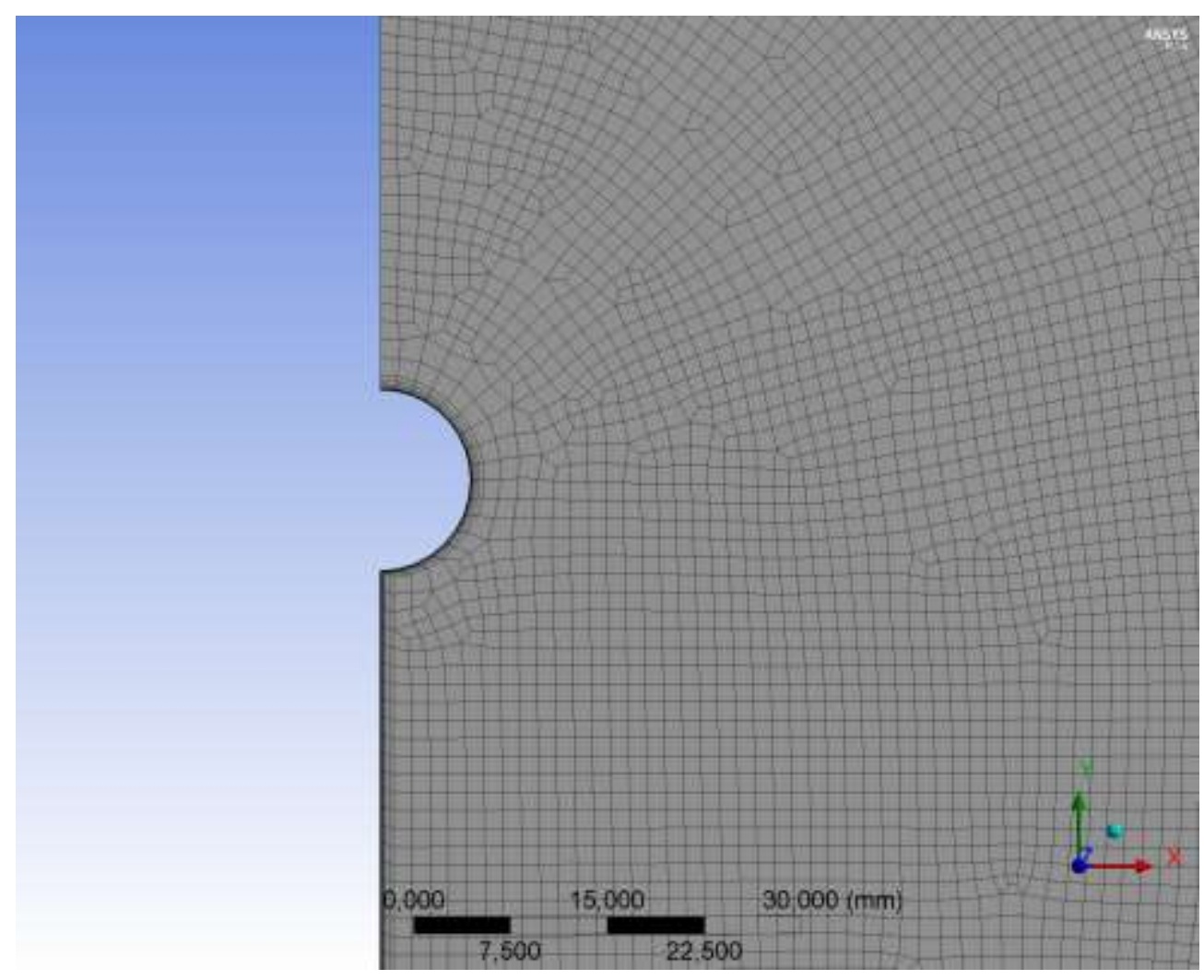

Fig. 2: Coarse Grid of the Model.

Table 1: Boundary Conditions.

\begin{tabular}{|c|c|c|c|c|}
\hline Depended Variable & B.C. at Upper part & B.C. at Right Hand Side & B.C. at Bottom (Outlet) & B.C. on Pipe Surface \\
\hline Temperature (K) & $T_{v=} T_{\text {sat }}\left(P_{\infty}\right)$ & $T_{v=} T_{\text {sat }}\left(P_{\infty}\right)$ & $\partial T / \partial x=0$ & \multirow{3}{*}{$T_{\text {wall }}=293.15 \mathrm{~K}$} \\
\hline Adsorbate pressure (kPa) & $P_{\infty}=10 \mathrm{kPA}$ & $P_{\infty}=10 \mathrm{kPA}$ & $P_{\infty}=10 \mathrm{kPA}$ & \\
\hline Adsorbate velocity (m/s) & $\begin{array}{c}\partial V_{v} / \partial n=0 \\
U_{v}=U_{\infty}\end{array}$ & $\begin{array}{r}\partial V_{v} / \partial x=0 \\
\partial U_{v / \partial x}=0\end{array}$ & $\begin{array}{l}\partial V / \partial x=0 \\
\partial U / \partial x=0\end{array}$ & \\
\hline
\end{tabular}

\section{Numerical Solution Method}

The solution domain is divided into quadrilateral control volumes in a non-orthogonal structured grid as seen Fig. 2 by using ANSYS Fluent Program.

The condensation model is triggered when the partial pressure of species in the bulk exceeds its vapor pressure at the film surface. The Fluent Lagrangian wall film model uses two different expressions for wall film condensation under laminar and turbulent flow conditions. The derivation follows, assuming that the condensation of species from the gas phase takes place in the presence of noncondensables. 
The number of mesh, max. skewness, and orthogonal quality are 29850, 0.68, and 0.67 respectively. A finite volume method is used to discretise the governing equations. A co-located variable storage scheme is used, so that all the variables are defined at the centre of a typical control volume.

Control volumes are cell-centred with one integration point on each face. Face velocities are calculated using a method based on a pressure-weighted interpolation method.

(1) Start with an initial coarse grid and a guess for the velocity, temperature and pressure fields.

(2) Calculate all coefficients based on the most recent fields.

(3) Solve for the U field implicitly in both phases.

(4) Solve for the V field implicitly in both phases.

(5) Perform the implicit, coupled solution for $\mathrm{U}$ and $\mathrm{V}$ in both phases.

(6) Solve for $\mathrm{P}=7 \mathrm{kPa}$ implicitly for the whole domain.

(7) Initialize wall thickness as 0,00001 m.

(8) Solve for T implicitly for the whole domain.

(9) Generate a new grid based on the most recent location of the interface.

(10) Repeat Steps 2-9 until steady-state convergence is obtained.

\section{Validation of the Results}

The model is validated by the results of $\mathrm{Li}$ and Peng [15] where $\mathrm{T}_{\text {wall }}=353 \mathrm{~K}, \mathrm{Re}_{\mathrm{D}}=68.5$ and $\mathrm{P}_{\infty}=1$ atm and gas mass fraction referring to the free stream or upstream conditions is taken as 0.01 .

The film thickness is compared for a tube diameter of $14 \mathrm{~mm}$. The normalised film thickness versus $\theta$ is plotted in Fig. 3. As can be seen from Fig 3, there is good agreement with the results of Li and Peng [15].

The validity of the present model is demonstrated by one comparison with earlier works for condensation on a horizontal tube: one for predictions of local film thickness. 


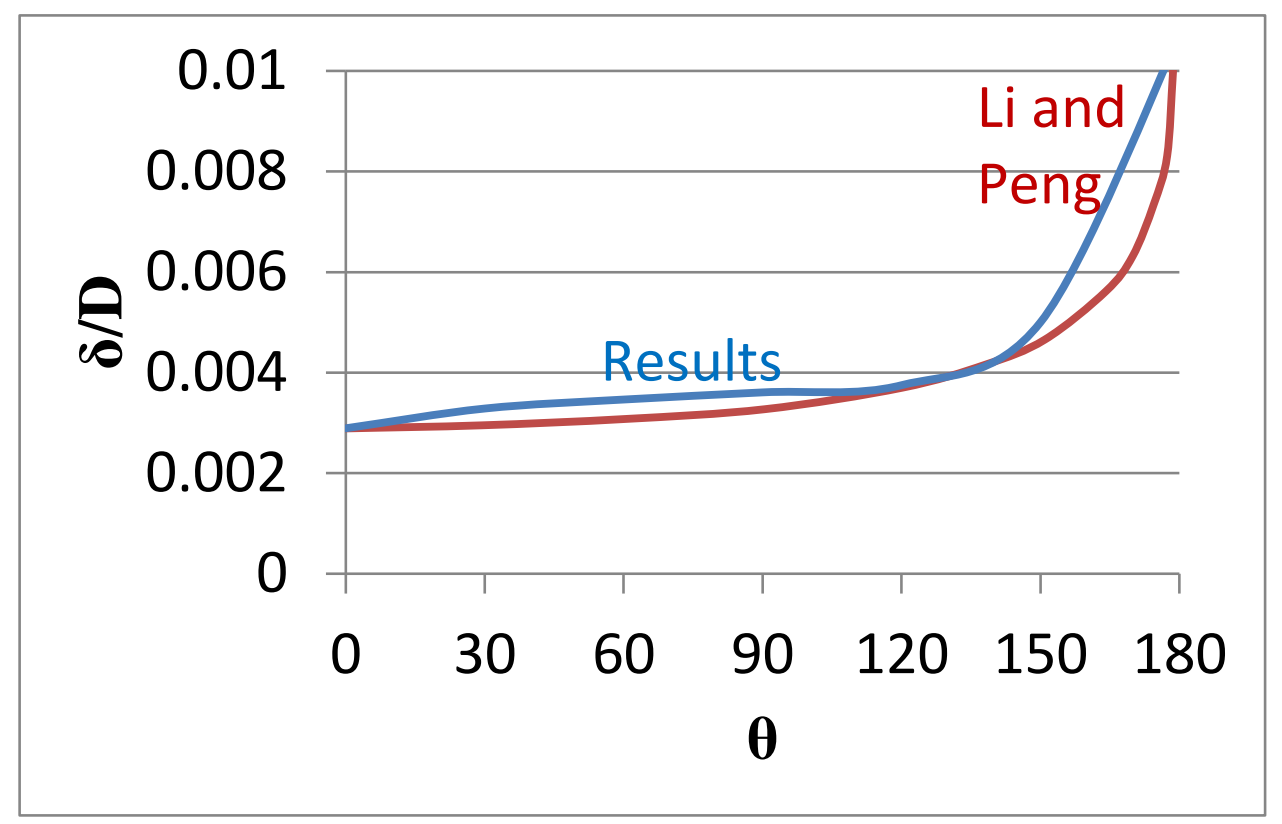

Fig. 3: Condensate Film Thickness Comparison with [15] for $\mathrm{ReD}=68.5$.

\section{Results and Discussion}

A detailed study was performed to examine the effect of changing independently the value of condensation rate on horizontal tube where only water vapour at $\mathrm{P}=7 \mathrm{kPa}$ inside of the domain. For all these cases, a tube diameter of $14 \mathrm{~mm}$ is used. Results were produced using the present model to study the effects of DT; ReD; and P1 on film condensation from a vertically downward uniform laminar flow of steam over an isothermal horizontal tube.

Water liquid volume fraction on fig.5 shows that the condensation mostly occurs between 120 and 180 degree. Film wall velocity is 0 , initial solutions shows that the coarse mesh leads wrong water phase wall thickness. In order to solve this issue mes size near walls are decreased to $0.00001 \mathrm{~mm}$.

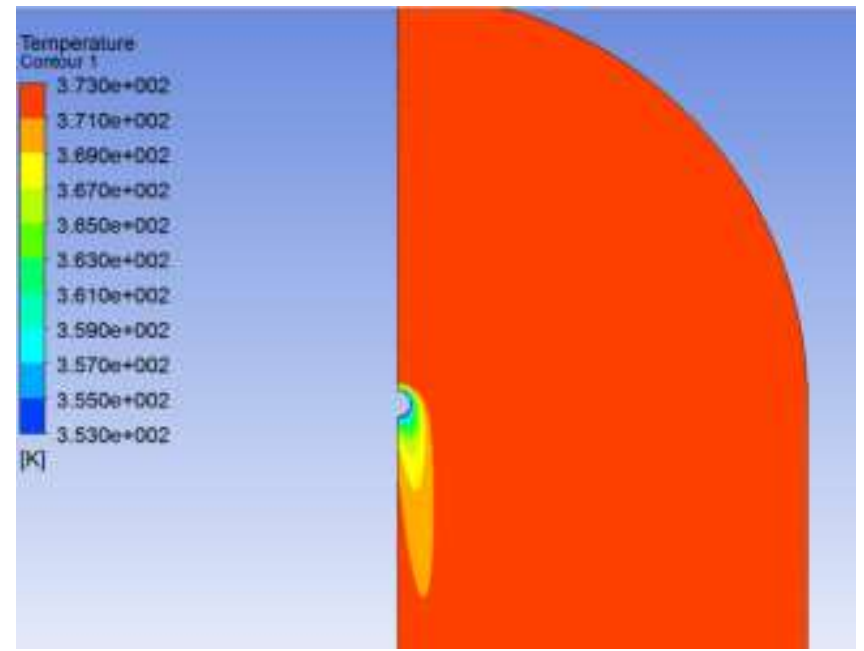

Fig. 4: Temperature Plot.

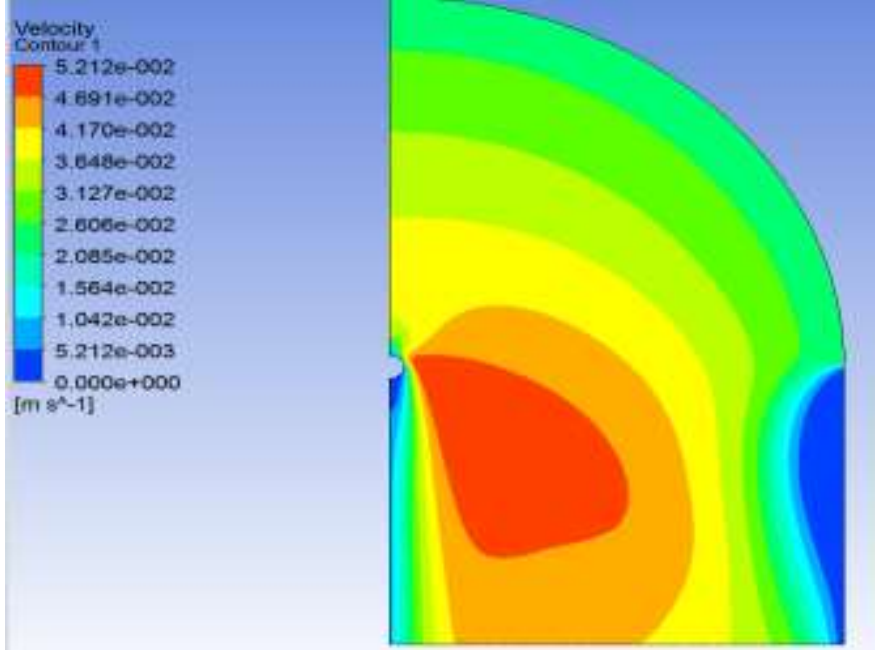

Fig. 5: Velocity Plot. 


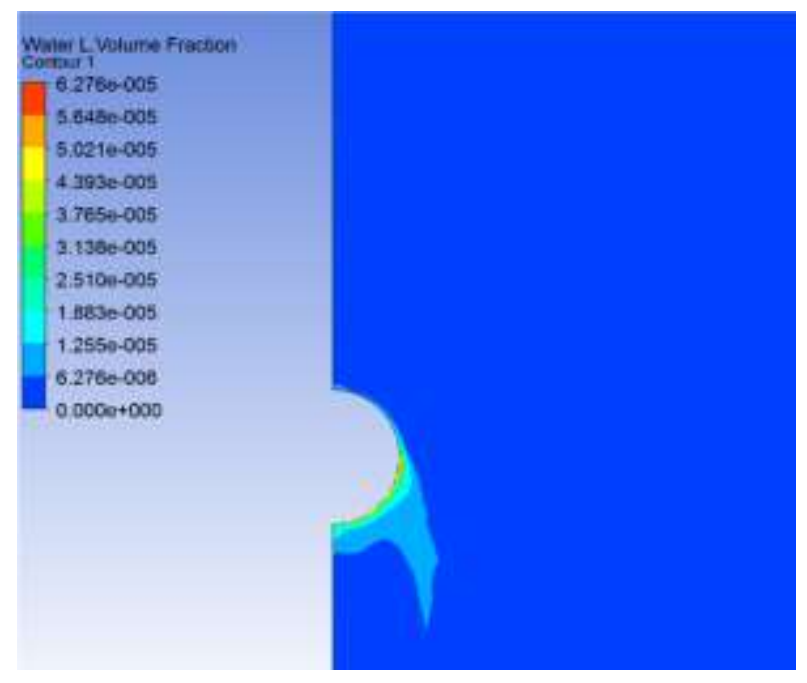

Fig. 6: Water Volume Fractio.

\section{Conclusion}

A numerical model for two phase laminar film condensation on an isothermal horizontal tube at steady state is presented in this study. 2D Navier- Stokes equations are solved for the model. For the validation of the solution, the comparison is performed and given in the study with good agreement.

Finally, the current numerical approach was applied again to Steam at $7 \mathrm{kPa}$ and used to show the condensation rate on the horizontal tube. The results showed that A complete two-phase numerical model was presented for steady laminar film condensation from a pure vapour over an isothermal horizontal tube.

Condensation can be defined as the transition from the gas phase to the liquid phase as a vapor condenses on a surface. The ANSYS Fluent film condensation model is triggered when the partial pressure of vapor species in the bulk gas mixture exceeds either its vapor pressure at the wall-film or, in case no film exists, at the wall temperature. When these conditions are met, the vapor species will condense and form the liquid film on the wall faces. There is no assumption of potential flow around the tube; the full viscous flow solution in the vapour is obtained. The current model was validated against the the two-phase model of Li and Peng [15].

Good agreement was achieved with the two models in predicting the thickness of the film developing around the tube. Finally, the current numerical approach was used to show the effects of changing the inlet-to-tube temperature difference, upstream Reynolds number, and saturation pressure on the condensation process. Changes in the inlet-to-tube temperature difference had the greatest effect on the condensation rate and film thickness. A moderate change in the upstream Reynolds number showed a slight increase in liquid mass flow rate with increased Reynolds number. Changing the inlet pressure demonstrated that property variation had a relatively smaller effect than temperature difference changes.

\section{References}

[1] G. G. Ilis, M. Mobedi, S. Ülkü, "Validation of Local Thermal Equilibrium and Uniform Pressure Assumptions for an Isobaric Adsorption Process in an Adsorbent Bed," J. Therm. Sci. Technol., vol. 36, pp. 37-45, 2016.

[2] H. Demir, M. Mobedi, S. Ülkü, "The use of metal piece additives to enhance heat transfer rate through an unconsolidated adsorbent bed," Int. J. Refrigeration, vol. 33, pp. 714-20, 2010.

[3] A. Alahmer, X. Wang, R. Al-Rbaihat, K. C. A. Alam, B. B. Saha, "Performance evaluation of a solar adsorption chiller under different climatic conditions," Appl. Energy, vol. 175, pp. 293-304, 2016. 
[4] M. Chorowski, P. Pyrka, "Modelling and experimental investigation of an adsorption chiller using low-temperature heat from cogeneration," Energy, vol. 92, pp. 221-229, 2015.

[5] W. Nusselt, "Die Oberflächenkondensation des Wasserdampfes," Zeitschrift des Vereines Deutscher Ingenieure, vol. 60, pp. 569-575, 1916.

[6] C. H. Hsu, S. A. Yang, "Pressure gradient and variable wall temperature effects during filmwise condensation from downward flowing vapors onto a horizontal tube," Int. J. Heat Mass Transf., vol. 42, no. 13, pp. 2419-2426, 1999.

[7] H. Karabulut and O. E. Ataer, "Numerical analysis of laminar film-wise condensation," Int. J. Refrigeration, vol. 19, pp. 117-123, 1996.

[8] M. Asbik, D. Ould Hadda, A. Il Idrissi, B. Zeghmati, A. Khmou, "Forced convection laminar film condensation of downward flowing vapor on a single horizontal elliptic cylinder or a bank of elliptical tubes," Numer. Heat Transf., Part A (Appl.), no. 37, pp. 511-544, 2000.

[9] C.-K. Chen, Y.-T. Lin, "Laminar film condensation from a downward-flowing steam-air mixture onto a horizontal circular tube," Appl. Math. Model., vol. 33, no. 4, pp. 1944-1956, 2009.

[10] M. Mosaad, "Forced convection film condensation of flowing vapour on an inclined circular tube," Heat Mass Transf., vol. 36, no. 1, pp. 1-6, 2000.

[11] C. K. Chen and Y. T. Lin, "Laminar film condensation from a downward-flowing steam-air mixture onto a horizontal circular tube," Applied Mathematical Modelling, vol. 33, pp. 1944-1956, 2009.

[12] M. Asbik, D. Ould Hadda, A. Il Idrissi, B. Zeghmati, A. Khmou, "Forced convection laminar film condensation of downward flowing vapor on a single horizontal elliptic cylinder or a bank of elliptical tubes," Numerical Heat Transfer, Part A, no. 37, pp. $511-544,2000$.

[13] Esam A. Saleh, Scott J. Ormiston, "A sharp-interface elliptic two-phase numerical model of laminar film condensation on a horizontal tube," International Journal of Heat and Mass Transfer vol. 102, pp. 1169-1179, 2016.

[14] Esam A. Saleh, Scott J. Ormiston, "An elliptic two-phase numerical model of laminar film condensation from a steamair mixture flowing over a horizontal tube," International Journal of Heat and Mass Transfer, no. 112, pp. 676-688, 2017.

[15] H. Li, W. Peng, "A study on gas-liquid film thicknesses and heat transfer characteristics of vapor-gas condensation outside a horizontal tube," J. Heat Transf., vol. 136, no. 2, 2014. 